\title{
Ser y vivir futbol en Juárez-México. Estampas culturales en un contexto de violencia y esperanza
}

\author{
Being and experiencing soccer in Juárez-Mexico. \\ Cultural prints in a context of violence and hope
}

\section{Luis Manuel Lara-Rodríguez*}

\footnotetext{
Sociólogo. Doctor en Ciencias Sociales. Profesor-investigador en el Departamento de Ciencias Sociales de la Universidad Autónoma de Ciudad Juárez. Líder del cuerpo académico «Cultura física, educación y sociedad». Docente de posgrado y pregrado. Es coordinador y coautor del reciente libro $D e$ porte y género (UACJ-UAEM, 2020).

-luis.lara@uacj.mx http://orcid.org/0000-0003$3112-5140$
}

RECIBIDO: 24.8.2021 ACEPTADO: 10.9.2021

\section{Resumen}

Ciudad Juárez-México, como otras tantas ciudades, concentran sus procesos de constitución identitaria entre escenarios y espacios encontrados, entre lo que se vive, se piensa y aquello a lo que se aspira de manera cotidiana. Frontera al norte de México, ha experimentado en las últimas décadas periodos de inseguridad pública y violencias, como los feminicidios y la «guerra» contra el crimen organizado. Pero, a la vez, durante las dos décadas finales del siglo XX y el XXI hasta la fecha, ha visto surgir una manifestación sociocultural en relación con el futbol profesional: la identificación con los equipos que han participado en el máximo circuito nacional. Juárez se ha caracterizado como una región aficionada al beisbol, el baloncesto y el atletismo, con cierto rechazo al futbol, sobre todo por su lejanía con el centro y el sur del país, donde este tiene un mayor arraigo. Aquí se describen algunas estampas socioculturales, a modo de representaciones sobre el futbol y la ciudad. Estas se inscriben en una conformación identitaria entre el sery vivir entornos de violencia, pero también de esperanza y exaltación, procesos que articulan lo migratorio, la dualidad, la díada centralismo-regionalismo, la influencia y el sentido entre lo nacional y lo internacional.

Palabras clave: deporte, manifestaciones culturales, sociología del tiempo libre, México. 


\section{Albstract}

Ciudad Juárez-Mexico, like many other cities, concentrates its identity constitution processes in scenarios and spaces of disagreement between what is experienced, what is thought, and daily expectations. Bordering northern Mexico, the city has endured periods of public insecurity and violence in recent decades, such as femicides and the "war" against organized crime. However, at the same time, during the final two decades of the twentieth century to date, a socio-cultural manifestation emerged concerning professional football (soccer): the citizens identification with the highest national circuit's teams. Juárez has been historically characterized as a region fond of baseball, basketball and athletics, with a certain rejection of soccer, especially due to its distance from the center and south of the country, where soccer is more firmly stablished. The article aims to describe some socio-cultural prints, as representations of soccer and the city. They are inscribed in an identity conformation of violence, but also of hope and exaltation, involving processes that articulate migration, duality, the centralism-regionalism dyad, national and international influences and meanings.

Keywords: sport, cultural events, sociology of leisure, México.

\section{Introducción}

México es un país de extensión amplia, con gran diversidad natural y cultural, esto último apegado a coyunturas de índole política (Béjar y Rosales, 2005). Ello incluye a los 32 estados que integran la república mexicana, y en estos, a sus municipios. Es el caso del estado Chihuahua y su referente principal, Ciudad Juárez, uno de los municipios fronterizos al norte de México.

Ciertamente la conformación de la ciudad ha sido compleja, y en las últimas décadas ha experimentado inseguridad pública y violencias como el feminicidio (Monárrez Fragoso, 2000, 2019), además de actos de exterminio y de lesa humanidad producto de la «guerra» contra el narcotráfico (Aziz Nassif, 2012; Arratia, 2017; Sumano, 2018), a la vez que desigualdad y vulnerabilidad social en diversos sectores de la ciudad (Medina Pérez et al., 2019). Sin embargo, la ciudad sigue, vive y se activa. Ciudad Juárez es muchos Juárez y es un gran espacio para el análisis social.

Así, por ejemplo, durante un periodo que cubre las décadas finales del siglo XX y el tiempo actual, ha visto surgir una manifestación sociocultural en relación con el futbol profesional, en específico, desde la identificación con los equipos que han participado en la liga de futbol profesional mexicano, que es lo que se tratará aquí. 


\section{El futbol, un fenómeno sociocultural}

A finales del siglo XX, la región chihuahuense se caracterizaba por que sus deportes predominantes eran el beisbol, el baloncesto y el atletismo (Rivera, 1999). Y, ciertamente, son las disciplinas que mayormente han producido a los y las deportistas profesionales chihuahuenses reconocidos/as nacional e internacionalmente (Juárez y LaraRodríguez, 2010). La vecindad con Estados Unidos permite que una disciplina como el baloncesto, y sobre todo el beisbol, se adentren en diversos lugares de México (Esparza Ontiveros, 2017), con mayor arraigo identitario en el norte, ante la lejanía del centro (política y cultural), como una de las principales vías de explicación; otras, sin oportunidad de desarrollar aquí, incluso plantearían por el factor migratorio ciertas condiciones antropométricas manifiestas con cierta tendencia en determinadas zonas mexicanas. Sin embargo, eso no significa que la práctica y la afición al futbol sean algo reciente en la región chihuahuense.

El futbol se juega y gusta desde ya hace muchas décadas, tanto en la práctica aficionada como en la recepción por televisión del futbol profesional mexicano y -acaso con mayor interés- del futbol internacional. Lo reciente es la difusión mediática por la presencia de equipos en el máximo circuito de futbol en México, específicamente los casos de Cobras, Indios de Juárez y F. C. Bravos. Ese acompañamiento mediático es importante, pero no el único; otro factor es el elemento migratorio, tanto de implicación local-nacional como binacional (Breceda y Nava, 2013), además de la globalización de la información mediante las plataformas de internet, que impactan en el ser hincha (Alabarces, 2018; Wood, 2021). Con la difusión en diversos espacios, el futbol consolida lo que prácticas locales-radiales como el beisbol y el baloncesto no terminaron de hacer. La fuerza del futbol llega a cualquier rincón, sobre todo a aquellos espacios donde las estructuras identitarias de otras disciplinas deportivas son incipientes o se han debilitado.

Ciudad Juárez se constituye con connacionales de otros estados de la república mexicana como Durango, Coahuila, Veracruz, Chiapas y la misma Ciudad de México, en los cuales el futbol tiene tradición en cuanto a la práctica, la afición y la organización de eventos, lo que ha contribuido a constituir afición, empresariado y practicantes de este deporte. Otro aspecto es la conformación empresarial-laboral, así como la educativa (educación media superior y educación universitaria) en la promoción recreativa y competitiva-representativa que integra al futbol (recreativo, aficionado, competitivo, semiprofesional), sin desconocer el efecto de lo popular, sea como demanda o como canal de contención a partir de dicha disciplina deportiva. Entre la industria, las instituciones escolares y las mismas administraciones públicas, la infraestructura del futbol y para el futbol daría cuenta de la habilitación de llanos, la adaptación y la implementación de canchas para torneos de futbol, incluso los estadios universitarios (de la Universidad 
Autónoma de Chihuahua, en Chihuahua capital, de la Universidad Autónoma de Ciudad Juárez, en Ciudad Juárez).

En el deporte, uno de los ejes para fortalecer la competencia es el fogueo. Es decir, jugar, competir con otros, los más posibles y lo más talentosos posible. Ciudad Juárez es un referente de competición estatal; mucho de ello se explica a partir de esa población, producto de las generaciones que han migrado, y de espacios de fogueo como el que se permite por la industria maquiladora.

La Asociación de Maquiladoras A. C. (AMAC-Index) es tal vez el referente de mayor calado dentro del deporte aficionado, principalmente el futbol. Si hemos de pensar en el desarrollo del futbol en la frontera, por supuesto que los equipos de primera división son estímulos de difusión muy fuerte, pero es la AMAC la que tal vez, por medio del fomento deportivo intramaquilador, constituido por una fuerte población emigrante del país a la frontera, mucha de ella futbolera, ha impulsado el germen futbolístico en la frontera.

Señalar que una ciudad integra diversas facetas o rostros no significa eludir que hay algunos elementos de arraigo, tanto positivos como negativos, que permiten integrar, dar color, a modo de estampas, que se van conjuntando de acuerdo a esos elementos de tradición, de recepción de lo que se vive y sabe de la ciudad, de lo que llega y va - personas, quehaceres culturales - no solo por los caminos y puentes físicos, sino también por sus puentes simbólicos producto de su condición de frontera norte (aspecto binacional ligado al proceso globalizador que en la ciudad impacta sobre todo a finales del siglo XX, tanto económica como culturalmente).

El futbol parece vivirse desde una irrupción a lo que «es tradicional y de suyo» del contexto norteño, el beisbol y el baloncesto principalmente. Una entrada a lo nacional, en un sentir acá - la frontera norte - también sabemos, podemos y logramos desde el futbol, lo cual va exaltando, como se ha sugerido, una vertiente de conformación identitaria. Además, como se señaló, el futbol es parte de la constitución cotidiana, desde las praxis y desde el ámbito de lo mediático en donde se vive afición, en donde la difusión sobre todo por medio de mundiales rebasa la promoción que se hace del beisbol, por ejemplo. Es decir, el futbol trae consigo una maquinaria popular nacional e internacional empresarial más fuerte que la promoción local de los deportes tradicionales; en ese sentido no solo es el consumo, sino producción, teniendo como máximo referente de ello el contar o haber contado con equipos locales en el máximo circuito del futbol nacional. Esto se refleja en infantes, jóvenes y adultos, sea desde su trayectoria que consume futbol, sea desde la dimensión del deporte praxis o el deporte espectáculo - o ambas(Cagigal citado por González Ramadall, 2004, p. 80).

La identidad se observa en diversos mecanismos culturales de arraigo desde referentes como el desierto, la industria obrera, el elemento binacional del cruce fronterizo, 
el elemento étnico, el factor migratorio, por mencionar algunos (más adelante se incluyen algunos de estos considerados como estampas culturales), los que se plasman también en los equipos, desde sus colores, motes, dinámicas de enunciación. Por ejemplo, la cobra como constitutiva del desierto; el guerrero equino - bravos - desde la fuerza y el ímpetu; el referente de indios, con relación a una de las etnias que tiene mayor notoriedad y difusión mediática, los tarahumaras.

\section{Estampas culturales, dimensiones de lo social en Ciudad Juárez}

Así, aquí concebimos como estampas culturales a aquellos que articulan emblemas regionales (platillos típicos, artefactos, paisajes, instituciones locales, etc.) con emociones y actitudes (de arraigo, de deconstrucción, de resistencia, de negación, de perpetuación) como una de las variadas versiones que se pueden expresar sobre un nosotros regional hacia lo nacional e internacional. En ese sentido, el futbol como elemento sociocultural es un dispositivo que se ensambla a distintas visiones de la ciudad, que ahora hace uso o performance de lo que estereotipa a la ciudad, ahora exalta lo que se quisiera se reconociera como el ser y vivir en la frontera juarense.

La práctica deportiva, desde su promoción, difusión, gestión y afición, no está exenta del entorno social en el cual se manifiesta en espacio y tiempo. La historia de Ciudad Juárez, respecto al deporte, desde su promoción como espectáculo y en su praxis, ha tenido diversas variantes disciplinarias, no solo el beisbol y el baloncesto. El atletismo, el boxeo, el ciclismo y la lucha libre, han generado diversas facetas de configuración del cotidiano juarense (Juárez y Lara-Rodríguez, 2010).

En cuanto a la práctica del futbol de Ciudad Juárez, siempre hubo un migrante que llegó, o un local que regresó de una estancia en el «interior» del país, o en otro país, quien se encargó de traer consigo la influencia del futbol. Al menos desde los años ochenta del siglo XX, sea por lo anterior o por la influencia de la televisión nacional que transmitía partidos del futbol nacional e internacional, en los municipios chihuahuenses también hubo tanto torneos como representativos de la disciplina. El balompié se insertó en el ámbito popular. Futbol en las calles, futbol en los recreos, futbol en los parques, en los llanos, futbol en la televisión, futbol en internet. Luego llegaría a la frontera norte del estado el futbol profesional.

Las siguientes estampas contribuyen al sentido de representación de una ciudad convulsionada, violentada a la vez que estigmatizada, a la cual se le señala ausencia de atractivos turísticos, alternativas de diversión distintas a la industria de la noche y del alcohol, variedad gastronómica incluso (Carrera, 2011). El futbol no está alejado de esas 
estampas, pues desde su organización empresarial como desde la afición conforma una estampa regional entre el anhelo del reconocimiento nacional, por un lado, como el rechazo ante esa idea de lo nacional como un fuera de, representado por otros equipos y aficiones (Llopis, 2009; Magazine et al., 2012). Antes, nos detenemos brevemente en señalar algunos aspectos de los tres equipos juarenses que han participado en la primera división profesional, regulada por la Federación Mexicana de Futbol (FMF).
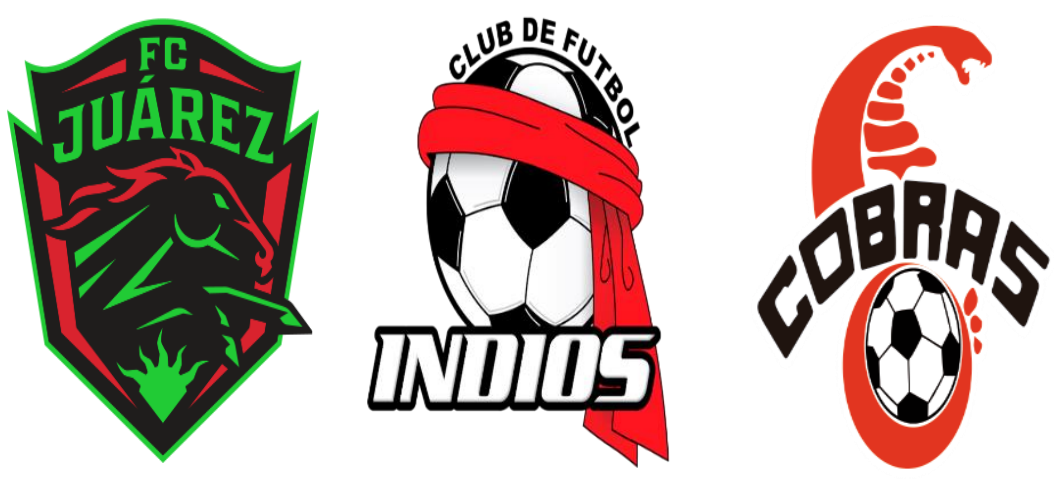

Figura 1. Logos oficiales de los equipos de primera división en la historia de Ciudad Juárez. Fuente: Internet.

Club Cobras de Ciudad Juárez. Su aparición y duración en el máximo circuito comprende de 1988 hasta 1992. En ese periodo, la ciudad vivió un auge de la industria maquiladora de exportación (Mendoza y García, 2018; Taylor, 2003), lo cual permitió una llegada de migrantes de ciudades de diversos estados del país, principalmente de Coahuila, Durango, Veracruz y de la Ciudad de México. En cuestión del contexto social, se configuraba un entorno de desarrollo urbano, a la vez que un sentido de incertidumbre sobre todo por efecto de las pandillas barriales (Alvarado, 2019). Dentro de los elementos simbólicos, Cobras hacía referencia al sentido de desierto (fauna) en su mote, y de los colores distintivos de la región, rojo y blanco. Su identidad se vio reforzada sobre todo por la inclusión y desempeño de jugadores nativos como Guayu Galván y de nacionales como López Zarza. Fueron tiempos de transmisión por televisión abierta (futbol mexicano, mundiales, futbol europeo, boxeo, beisbol de grandes ligas y futbol americano). Tiempos del esplendor de iconos nacionales como Hugo Sánchez, Fernando Valenzuela y Julio César Chávez.

Club de Futbol Indios. Tuvo una estancia fugaz pero sui generis en primera división (2008-2010), muy significativa en el sentir de la ciudad. Un equipo sorprendente 
en Liguilla y luego una caída abrupta con malos números que impusieron récord de juegos no ganados hasta aquel momento (año 2010). En el aspecto social, generó una efervescencia de la afición en uno de los momentos con mayor incertidumbre y miedo social: el periodo 2008-2012 fue de máxima violencia e inseguridad exacerbada en la ciudad, la ciudad más peligrosa del mundo (Salazar, 2010; Arratia, 2017). Los colores, rojo y blanco. El logo, un rostro de balón con pañoleta en la frente, en alusión a la etnia tarahumara y a otras que habitan el estado, elemento cultural de apropiación de uno de los sectores poblacionales más tradicionales a la vez de vulnerables y oprimidos históricamente del estado.

La identidad de Indios se vio reforzada por la inclusión de locales como Maleno Frías, nacionales como Tomás Campos, Edwin Santibáñez y de extranjeros como el colombiano Andrés Chitiva y el argentino Juan Augusto Gómez. Un periodo de televisión por cable, difusiones y transmisiones incluso por internet y redes sociales, además del auge de la plataforma YouTube, en donde se podían (pueden) visualizar casi a tiempo real tanto un gol como una jugada.

FC Juárez-Bravos. El equipo milita en primera división desde el 2015. FC Bravos llegó a llenar el hueco y nostalgia que había dejado Indios de Ciudad Juárez. Ha tenido continuidad, chispas de protagonismo, pero no ha generado aún el impacto estatal que en algún momento logró Cobras al ir contracorriente en un Chihuahua ajeno al futbol profesional, como tampoco ha tenido los momentos de protagonismo nacional que registró Indios. Sus colores son el rojo sobre un fondo negro y verde, en alusión al logo de la principal empresa de la familia De la Vega. Bravos adopta en el centro de su playera, la X, una escultura monumental, a encargo y factura de la administración municipal en 2013, por una cantidad de alrededor de 9 millones de dólares, la que se ha promocionado oficial y mediáticamente como emblema de la ciudad.

Entre los jugadores referentes destacan Leandro Carrijo y Eder Borelli, jugador brasileño y mexicano-argentino, respectivamente; ambos ahora jugando en El Paso Locomotive FC (USL Championship), ante la no renovación de contrato por FC Juárez a mediados de 2020. Ha contado con jugadores y entrenadores importantes, pero aún no han asentado una influencia y trayectoria relevante. Un elemento importante es la emergencia de equipos de mujeres dentro de las instituciones profesionales (Liga MX Femenil, a partir de 2016-2017).

FC Bravos, por ser parte de los equipos del máximo circuito, aporta esa nueva faceta de análisis que Cobras e Indios no tuvieron. Son los tiempos de los derechos de transmisión, desde los canales de televisión abierta, y las concesiones en espacios en internet, lo cual, a la fecha, no son algo a considerar — al mismo nivel- para la liga de beisbol y el baloncesto profesional o universitario.

Estos tres equipos han sido producto de lucha en la división de ascenso, auge y emoción local, efecto de compra de franquicias, sorpresa o curiosidad nacional, y desaparición. 
Es decir, una suerte de levantarse desde el sustento económico, bregar en un escenario desconocido o no dominado, como lo es la empresa del futbol profesional, aprovechar la industria cervecera y de comercialización de marcas, de la construcción, de las sociedades y negociaciones, así como ir sembrando la semilla de un arraigo futbolero en la región. Una industria cervecera y de la construcción (Chávez et al., 2019) está detrás de dichos equipos: causante de la leyenda negra para algunos, promoción turística para otros -el alcohol-; crecimiento y desarrollo urbano para unos, urbanización mal planeada acompañada de segregación y precarización de servicios para otros - la construcción-. Dentro de estos intersticios hay estampas, reflejos, representaciones y conformaciones que permiten un sustento discursivo respecto al ser y vivir Ciudad Juárez. Veamos algunas de ellas.

\section{El desierto}

La imagen del desierto en la región del Valle de Juárez es importante dentro de la constitución de imaginarios y representaciones: como los vencedores del desierto. No solo implica vencer en un espacio que demanda el agua como un elemento de sobrevivencia, sino también la imagen de una construcción de ciudad desde condiciones hostiles. Para el juarense esto se implica sobre todo desde las estaciones del año, pues se jacta de vivir un clima extremoso, de calor, frío, polvo, cambios en un mismo día. Estas situaciones, por supuesto, no son exclusivas de Chihuahua en lo general, ni de Ciudad Juárez en lo particular. Hay estados y municipios más calientes y fríos que Ciudad Juárez. Sin embargo, la idea de que en Ciudad Juárez eso es una constante, permite a sus habitantes fortalecer aquello de vencer climas, o diversas situaciones en su día cotidiano.

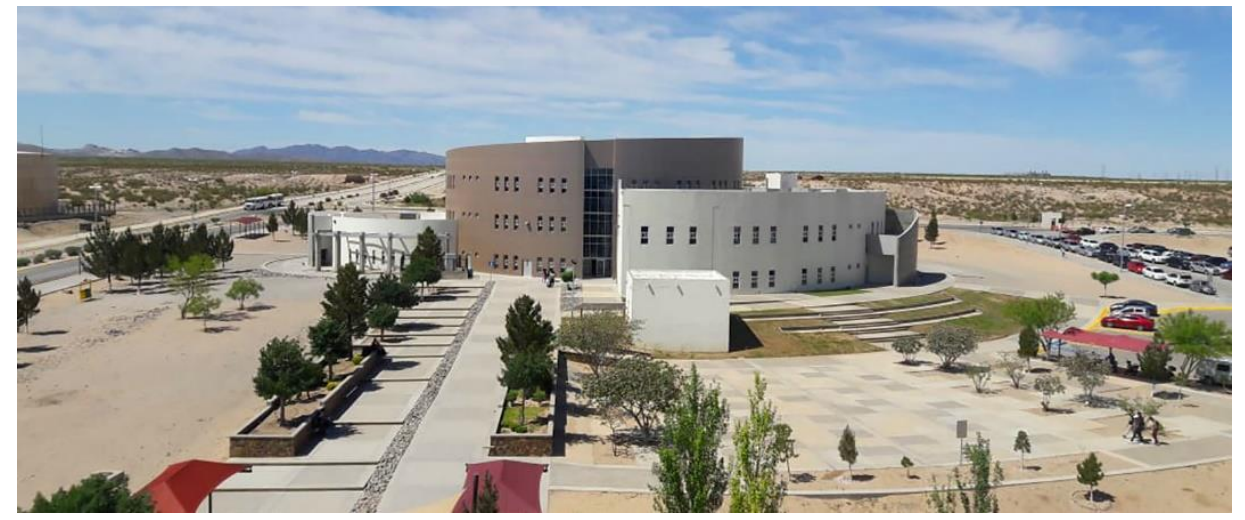

Foto 1. División Multidisciplinaria en Ciudad Universitaria-UACJ, Ciudad Juárez. Fuente: UACJ. 


\section{La frontera, el shopping y la industria cervecera}

El cruce binacional Ciudad Juárez-El Paso-Texas, tiene como referente que muchas personas viven, trabajan o estudian, y consumen en el lado americano. Por supuesto, la ciudad fronteriza mexicana no se puede desprender de la referencia a El Paso, tanto en cuestión de economía, política binacional, como en cuestión cultural por los cruces cotidianos. Ciudad Juárez, en el imaginario para el centralismo, permanece como una ciudad a la cual se le cuestiona contar con limitadas opciones de turismo, a no ser los centros antiguos, o allende los centros arqueológicos.

La vida nocturna y el comercio binacional son lo que permanece mayormente en el imaginario de la ciudad para muchos extranjeros y foráneos nacionales. La frontera norteña consolida una vida nocturna en donde las empresas cerveceras tienen auge. No es casualidad que Cobras y FC Bravos ha sido y son de familia en este ramo. Otro aspecto es que la industria del alcohol, tanto en su dinámica ilegal como legal, es un referente para lo que constituiría real y discursivamente la leyenda negra de Ciudad Juárez (García Pereyra, 2010).

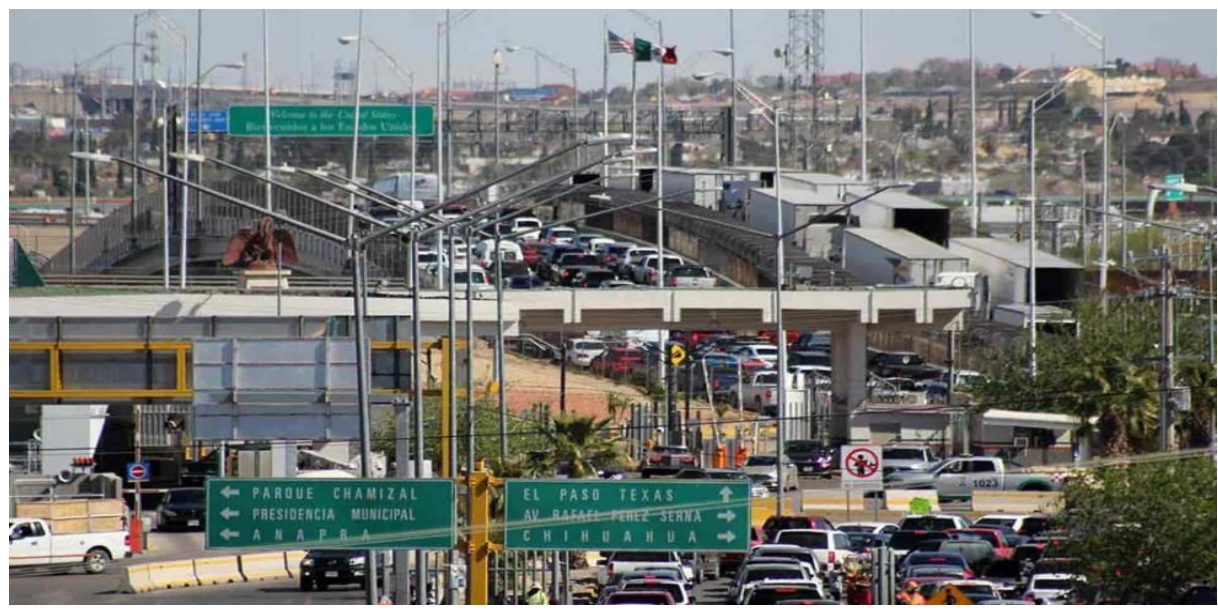

Foto 2. Puente Córdova Américas, Ciudad Juárez-El Paso TX. Fuente: lasillarota.com 


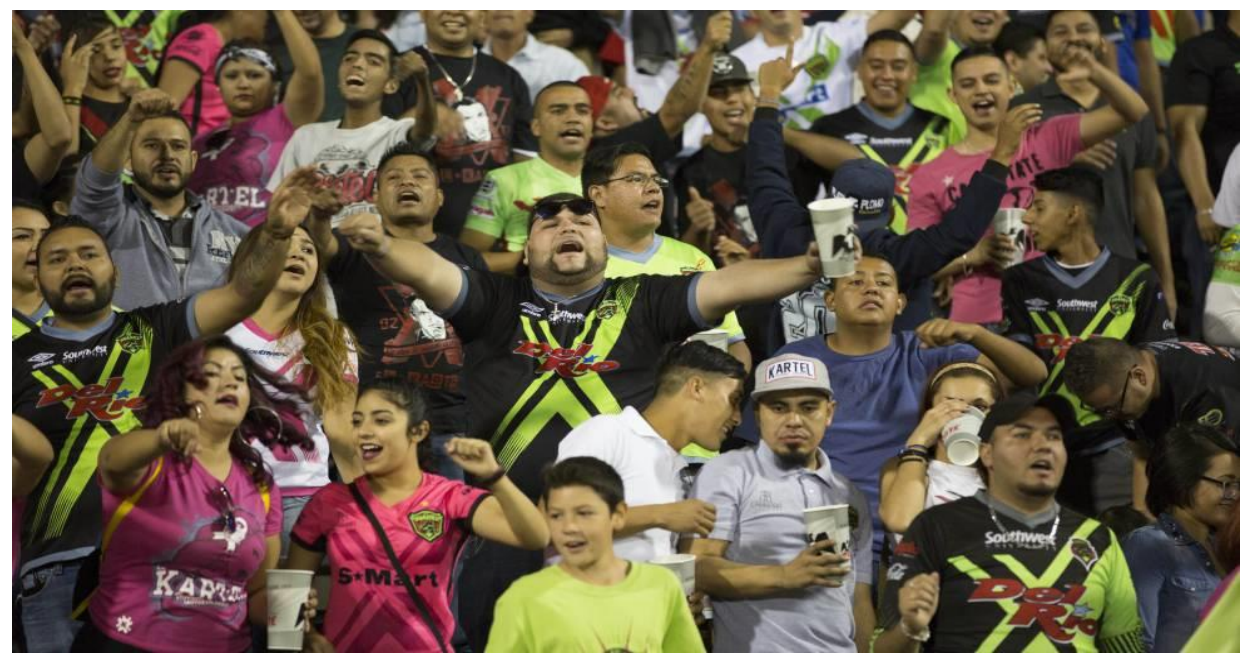

Foto 3. Afición en el estadio, apoyando a FC. Bravos. Fuente: elpais.com.

\section{La industria maquiladora}

La industria maquiladora es uno de los ejes que impulsan el desarrollo económico de la ciudad, influenciando o impulsando la necesidad de servicios de vivienda, movilización y de abastecimiento, por mencionar algunos. Hay otro elemento, el de los principales actores de este ramo, obreras y obreros, quienes en un imaginario de la ciudad son los maquilocos, es decir, son el primer referente para aquella faceta discriminatoria y clasista del juarense.

El aspecto migratorio en Ciudad Juárez no lo es solamente por constituirse en vecindad con una región de Estados Unidos, sino también por la demanda de mano obra que, en etapas de su historia, la industria maquiladora de la región fronteriza ha requerido. Mano de obra migrante, asentada en un espacio en el cual se aduce que si vives en Juárez, eres de Juárez, pero en donde también se acusa al otro, al foráneo, de ser el causante de los problemas de la frontera ante la falta de arraigo y amor por la ciudad. En ese sentido, Ciudad Juárez no solo es tierra de norteños, sino que se conforma de una gran parte de oriundos de la Comarca Lagunera, del centro y del sur del país, estados con mayor tradición y arraigo futbolero, lo cual ha permitido generar ese germen de difusión futbolística aparejado elementos de identidad popular y de cultura de diversos estados del país. 


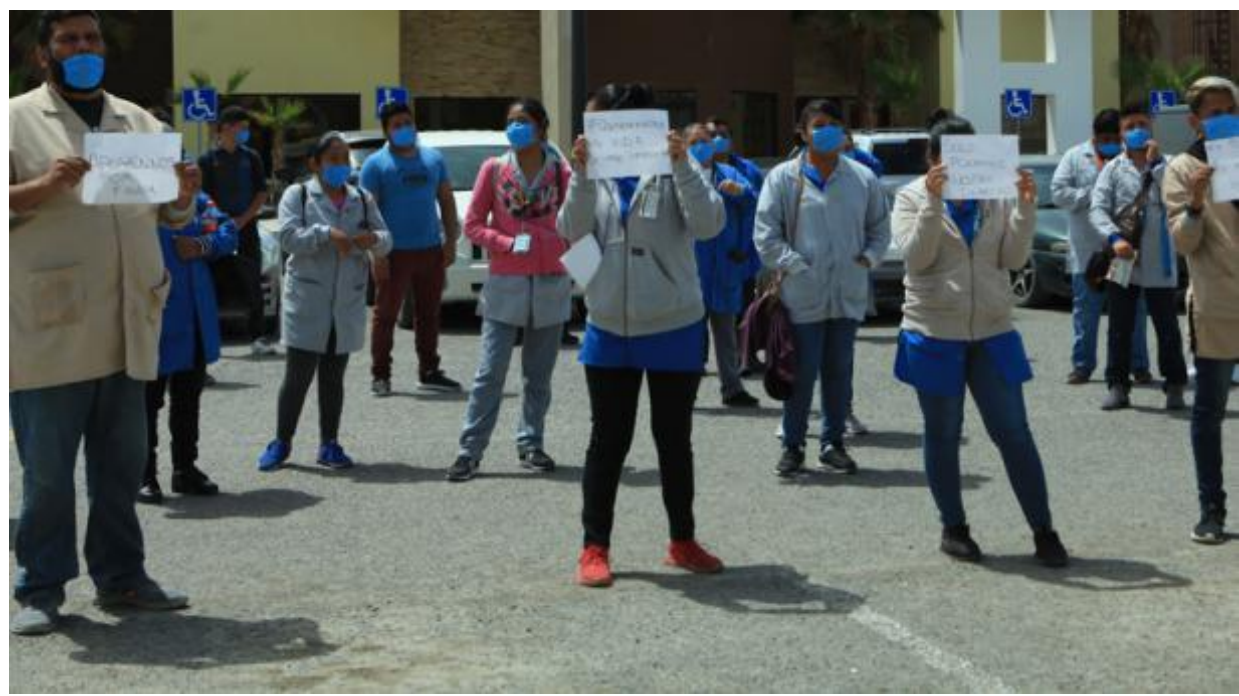

Foto 4. Obreras y obreros de la industria maquiladora. Fuente: elcomercio.com

\section{La identidad en/desde el futbol}

En México, la referencia al aguante (Alabarces y Garriga, 2008), como en Sudamérica, se podría entender como la conformación de identidad y un empuje, resistir, afrontar con lo que es nuestro: nuestro cuerpo, nuestras marcas, nuestra piel. Y la piel en el futbol, para un hincha, es aquella que se vuelve una entre el yo y lo que implica mi playera (remera). Ciudad Juárez encontró en Indios de Ciudad Juárez un referente de afición como antes no hubo, y que ahora, en cierta forma, ha heredado FC Bravos.

Tal vez esa afición es única, porque surgió en el momento más fuerte y violento de la ciudad en su historia moderna, cuando más se ha sentido la incertidumbre social y el miedo de salir a las calles (similar — con distintos matices - a lo vivido con la pandemia de covid-19). Conviene señalar que los cuerpos de afición aún siguen siendo predominantemente varones en el apoyo. El Kartel, de entre todas las porras, ha mostrado un dominio, desde un mote que aun cuando parece buscar vaciar el sentido de estereotipo (narcos juarenses), lo sigue perpetuando el contrario para el imaginario social del visitante. 0 acaso pretende, desde dicho mote, un recurso masculinizado para exponer dureza, desde aquel tipo de condición masculina que privilegia o supone que mientras más temor infunda, gana. En lo femenino no hay porras, son las mismas del entorno Bravo: el campo sigue siendo un dominio de varones. Hay representatividad de mujeres en FC Bravos: la propietaria es mujer, el personal médico es ejercido 
por mujeres, y por primera vez una entrenadora en la temprana historia de Bravas, Tity González, asumió el cargo. Sin embargo, el futbol mexicano todavía se rige desde una dominación masculina.

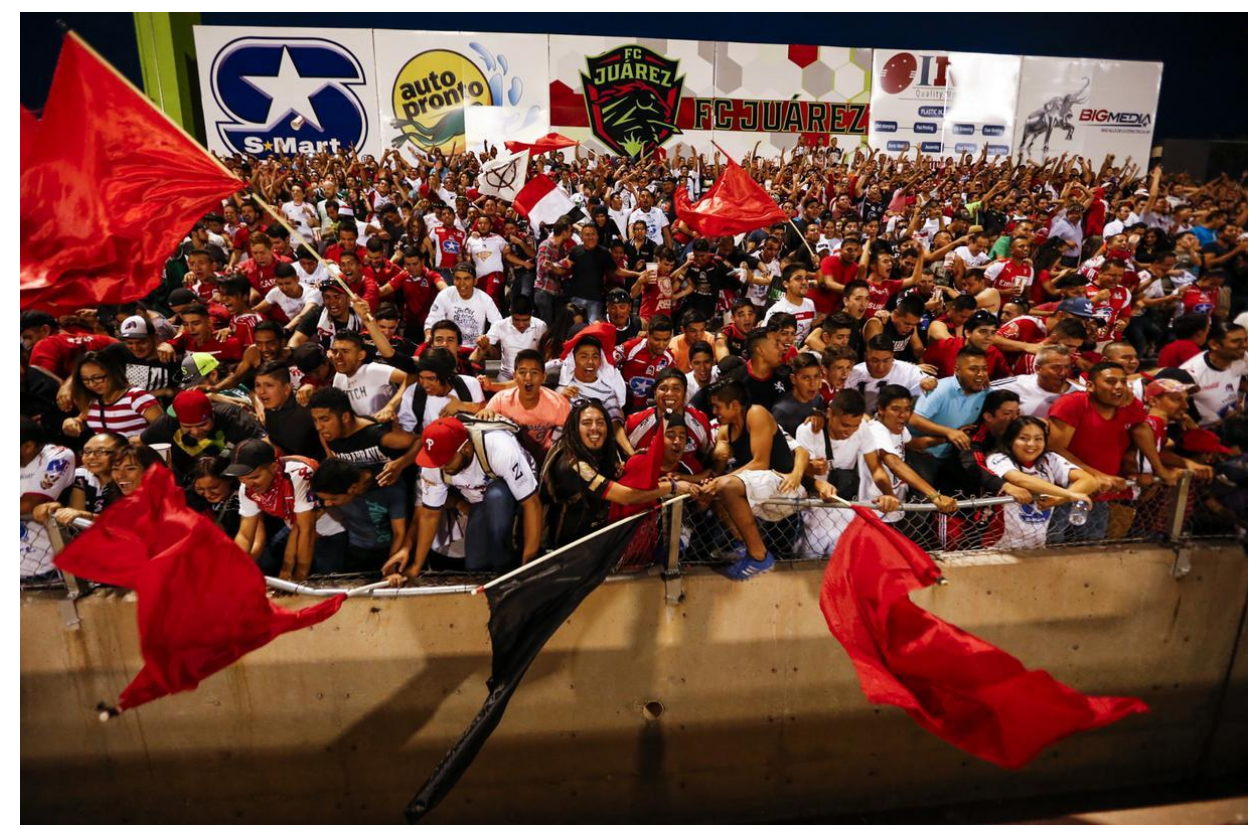

Foto 5: Aficionados con playera de Indios, en tiempos de FC Bravos. Fuente. apuntesderabona.com

\section{La lucha de mujeres}

En un momento de un juego entre equipos femeniles, en el 2002, los aficionados gritaban jocosamente en el estadio Benito Juárez (como pretendiendo inventar «el hilo negro» del humor): «iLe pegas como niña, le pegas como niña!». Pareciera que ver jugar a mujeres para un segmento de la afición futbolera era/es causa de gracia. Mientras que, para muchas mujeres, la inseguridad de la ciudad era/es causa de temor e indignación. El futbol femenil es previo al inicio del siglo XXI, al menos una o dos décadas, en distintos lugares del mundo. Incluso, en algunos municipios del estado, sobre mediados de los noventa, ya había una serie de juegos dentro de la liga de futbol aficionado.

En el inicio de la aventura futbolística de Bravas de Juárez, los medios de comunicación y la misma plataforma de Facebook de FC Bravos consideraban a las jugadoras 
como «Bravitas», infantilizándolas. Desde las redes sociales se logró el cambio, principalmente por observaciones con perspectiva de género y/o talante feminista, de que se refieran a ellas como Bravas de Juárez. Por otro lado, si la máxima revolución de fines del siglo XX y de este siglo es feminista, Ciudad Juárez es uno de sus escenarios (Rojas Blanco, 2020). Pero el feminismo y la lucha en contra de las violencias de género, sobre todo el feminicidio (Monárrez Fragoso, 2019), no abarca todos los escenarios cotidianos de la ciudad. Hay mujeres feministas que juegan futbol aficionado, pero hay muy pocas mujeres futbolistas profesionales que sean feministas o con una perspectiva de género profunda. La sociedad misma, se puede señalar, no entiende el feminismo (o feminismos), lo que implica que no haya aún figuras mexicanas feministas en futbol profesional mexicano. En ese sentido, Ciudad Juárez es un escenario de reflejo de un tipo de cultura machista, pero también lo es, o lo puede ser, su desestructura necesaria, incluso desde el deporte.

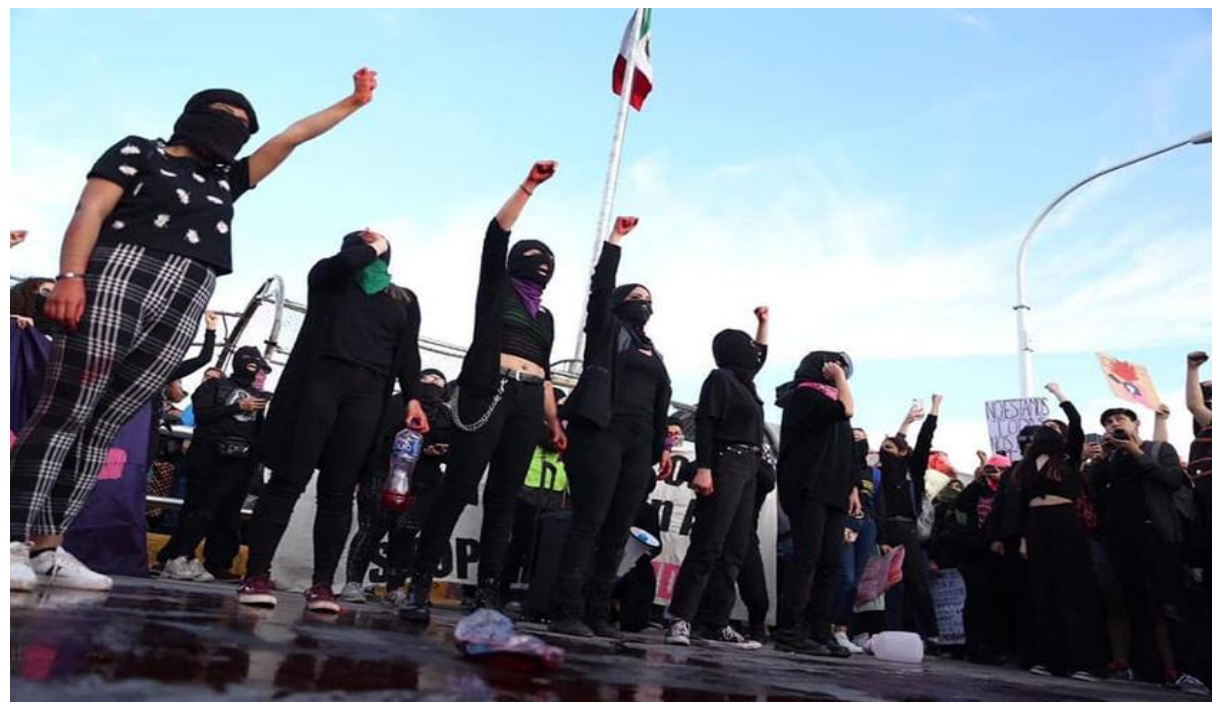

Foto 6. Manifestación de mujeres en Ciudad Juárez. Fuente: Vocesfeministas.mx

\section{El centralismo y la otredad}

Era común escuchar al comentarista deportivo Enrique Bermúdez, de una de las televisoras nacionales (Televisa), narrando los partidos en que se involucraba el equipo de futbol Santos Laguna señalar que este tenía el apoyo de todo el norte del país; todavía 
no existían los Xolos de Tijuana, no estaba de nueva cuenta Cobras y todavía no aparecían Indios y FC Bravos. Aquella postura es propia de un centralismo cultural que asigna que, si es originario o radica en el norte, entonces apoyan al «Norte». A Ciudad Juárez no solo le distingue sentirse doblemente excluido o marginado, o definido, sea por el centralismo federal (Ciudad de México, capital) o por el centralismo estatal (Chihuahua, capital), sino por quien parece ostentar en el imaginario nacional la condición de ser «el norte»: Nuevo León, o más específico, la ciudad de Monterrey, capital del referido estado.

Pero Juárez también excluye - conformando una suerte de centralismo alterno- a las ciudades al sur del estado y a los mismos estados mencionados. Por ejemplo, así, ha sido parte de la estampa identitaria la consignación de motes despectivos como el de juarochos para las personas que cubren un acento con características del sur (pero diferenciado de acuerdo con sus regiones), siendo indiferente al hecho de que Ciudad Juárez se ha constituido no solo de personas del estado de Veracruz, sino también de Chiapas y Tabasco, principalmente. En ese sentido, sectores de la ciudad son consignados como habitantes del sur, por ejemplo, «Riveracruz» en alusión a las nueve etapas del fraccionamiento Riveras del Bravo, tal vez uno de los sectores no solo más olvidados por administraciones gubernamentales, sino también estigmatizados y estereotipados por la comunidad juarense. De ahí se explica también el rechazo a Tiburones Rojos de Veracruz (desafiliado de la Liga en 2019), un equipo con mayor arraigo nacional y tradición que los equipos fronterizos. En ese sentido, un juego entre dichos equipos no solo integra aficiones locales, sino sentidos de revancha y constitución regional.

Para Pablo Vila (2007), independientemente del sentido de racismo imperante en México, y a lo cual no escapa Ciudad Juárez, la nación mexicana tiene también un sentido regionalista que se evoca en diversas manifestaciones culturales, una de ellas, la afición y apoyo a equipos de futbol profesional.

También ha sido significativa la intensidad puesta en partidos en contra de La Laguna, con Santos, un equipo cuya historia ha sido más prolongada, afianzada y con triunfos que los equipos fronterizos. Situación similar se da con el equipo distintivo de otra frontera norte, Xolos de Tijuana, con mayor duración en el máximo circuito y protagonismo que los equipos fronterizos.

Eso pesa, eso provoca, eso constituye al futbol profesional, de una forma más compleja que lo que sucede en el beisbol y el baloncesto, en donde sus contactos de identidad son locales, es decir, representados en ligas estatales. Ni el beisbol ni el baloncesto han logrado lo que el futbol: exaltar las identidades por medio de la triada regionalismonacionalismo-concierto internacional, pues aquellos - el beisbol y el baloncesto- se han quedado en lo local. 


\section{Conclusiones}

Si en lo general Ciudad Juárez es posible que a ojos y oídos de foráneos y locales remita inseguridad, no es un desatino que, a otros y otras, les llame como un espacio de alegría y hospitalidad. Lo que es seguro es que es todo eso, tanto escenario de violencias como de esperanzas y resiliencia. En ese sentido, presenta diversas peculiaridades en lo que respecta al análisis del futbol. Es una ciudad al norte de un país que ha sido centralista en sus políticas y en la difusión mediática desde sus principales televisoras Televisa y TV Azteca (medios de los cuales se ha manejado la referencia hacia quienes no son de la urbe metropolitana como parte de provincia, aun desde esa dimensión independentista y centralista).

Hemos señalado como estampas a esos reflejos a modo de representaciones de lo que se sustenta como el ser juarense o plantearse como el ser parte de la ciudad. El futbol, por medio de la promoción de sus equipos, no escapa a ello, pues también reproducen estas ideas de vencedores del desierto, fortaleza, ímpetu, lo bravío, lo productivo, lo innovador, elementos que buscan contrarrestar el estigma de la historia o faceta negra de la ciudad, de la exclusión binacional, por un lado, la nación por el otro lado, el rechazo y/o dependencia internacional, sobre todo del vecino estadunidense.

Enmarcar algunas estampas del ser, sentir y moverse en Ciudad Juárez no tiene desapego con la promoción de identidad de los equipos de futbol, o de los sentires de sus aficionados desde lo regional respecto hacia esa idea de lo nacional (Magazine et al., 2011). Así, el desierto y la resistencia son elementos importantes dentro del imaginario del estado chihuahuense, aunado a la situación del norte como cuna de la nación, pues ahí fue donde se asentó uno de los mayores emblemas — desde la difusión oficial— de la identidad político nacional: el Benemérito de las Américas, Benito Juárez García.

El desierto en una franja fronteriza, la salida o entrada norte del país — según se vea- con vecindad con Estados Unidos, conlleva miradas desde el afuera y desde el adentro, en donde la idea de ausencia (de vida, de color, de contraste) puede ser el bastión de lucha de quienes la habitan, y conforma esa vida, ese color, ese contraste, de manera distinta, particular, un estilo, una identidad.

La identidad con el futbol obedece en mucho al elemento de la migración. Sobre todo, cuando se considera que la migración no solo es una dinámica económico-política, sino que también conforma un caldo de cultivo cultural en donde no está exenta la discriminación clasista.

Ello, en cuanto al futbol, contribuye en estampas de conformación identitaria desde aficionados asentados en Ciudad Juárez, principalmente provenientes de los estados de Coahuila y Veracruz, en donde muchos de esos aficionados apoyan a equipos de primera división como el Club Santos Laguna y al desaparecido Tiburones Rojos de 
Veracruz. También hay quien proviene de la Ciudad de México, de las ciudades de Guadalajara y de Monterrey, tres de los sitios más importantes en cuanto a la tradición futbolística en el país, de donde son los equipos con mayor peso económico y palmarés del futbol mexicano. Es decir, en Ciudad Juárez, conformar afición futbolística para sus equipos se hace dentro de un escenario en donde el migrante se decanta por sus elementos identitarios, sean regionales, sean de estímulo televisivo-virtual nacional e internacional (apoyan a sus equipos al no contar con la oportunidad de verlo jugar de manera presencial, por no residir donde el equipo).

Por otro lado, Ciudad Juárez por ser norte no implica que apoye lo regional, sobre todo en manifestaciones como el futbol. Así, es muy común encontrar una fuerte y amplia afición futbolística con equipos como el América, el Guadalajara, los Pumas de la UNAM, Cruz Azul y, en una medida más de índole regional, Rayados del Monterrey, Tigres de la UANL y Santos Laguna (no se diga por equipos europeos y en menor medida por equipos sudamericanos).

De este modo, uno de los clásicos regionales, al menos visto así por los juarenses, es en contra de Santos, en sentido más regionalista que por choque de palmareses. En cambio, cuando son juegos en contra de los equipos grandes, América y Guadalajara principalmente, el apoyo es hacia esos equipos, pues son los «nacionales», pues la localía aún no pesa por sobre la imagen y la celebridad que ha encontrado arraigo desde los años setenta del siglo XX.

El futbol en Ciudad Juárez paradójicamente encontró su mejor impulso como oferta cultural y pudo consolidar afición no por un palmarés nacional o internacional que no ha sucedido-, sino en un momento de incertidumbre y temor social a razón de la inseguridad pública y la violencia en donde la ciudad figuró en el concierto de los lugares más peligrosos del mundo, entre 2008 y 2012.

A partir de Indios de Ciudad Juárez se inició una afición propiamente, resiliente, más identificada con el ser y vivir una frontera. Hablar de la historia de los equipos de futbol de primera división en Ciudad Juárez es tener en cuenta su proceso histórico, sus coyunturas, el juego entre la promoción identitaria y la reivindicación de estigmas como la industria del alcohol, la desigualdad social, el desarrollo descontrolado y mal planeado. Las estampas culturales de un espacio-momento, desde el futbol, también representan lo que se ha sido, se ha vivido y lo que se aspira ser.

\section{Referencias bibliográficas}

Alabarces, P. (2018). Historia mínima del fútbol en América Latina. México: El Colegio de México. Recuperado de https://libros.colmex.mx/wp-content/plugins/documentos/descargas/HM_futbol_America_Latina.pdf. 
Alabarces, P., y Garriga, J. (2008). El “aguante”: Una identidad corporal y popular. Intersecciones en Antropología, 9, 275-289. Recuperado de https://www.redalyc. org/pdf/1795/179514533020.pdf.

Alvarado, T. (2019, 25 de junio). El día que el narco desterró a las pandillas de barrio. El Heraldo de Juárez. Recuperado de https://www.elheraldodejuarez.com.mx/local/el-dia-que-el-narco-desterro-a-las-pandillas-de-barrio3812117.html/amp.

Arratia, E. (2017). Todos somos Juárez: Competition in state-making y la guerra contra el narcotráfico (2006-2012). Revista Española de Ciencia Política, 43, 83-111. DOI: $10.21308 /$ recp.43.04.

Aziz Nassif, A. (2012). Violencia y destrucción en una periferia urbana: El caso de Ciudad Juárez, México. Gestión y Política Pública, 21, 227-268. Recuperado de http://www.scielo.org.mx/pdf/gpp/v21nspe/v21nspea7.pdf.

Béjar, R., y Rosales, H. (2005). Las identidades nacionales hoy: Desafíos teóricos y políticos. En R. Béjar y H. Rosales (coords.), La identidad nacional mexicana como problema político y cultural: Nuevas miradas (pp.15-35). Cuernavaca: UNAM.

Breceda Pérez, J. A., y Nava González, W. (2013). Contexto y flujos migratorios en Ciudad Juárez, Chihuahua-El Paso, Texas. Noésis: Revista de Ciencias Sociales y Humanidades, 22, (43-1), 254-280. DOI: 10.20983/noesis.2013.1.8.

Carrera, J. (2011). Cultura, carne asada y balazos. Chihuahua: Jorge Carrera.

Chávez, J., Maycotte, E., y Sánchez Flores, E. (2019). Vivienda y movilidad social en Ciudad Juárez, Chihuahua 2002-2010. Vivienda y Comunidades Sustentables, (5), 6172. DOI: $10.32870 /$ rvcs.v0i5.111.

Esparza Ontiveros, M. A. (2017). Notas para la historia de los deportes en México: El caso del béisbol capitalino (1910-1920). Revista de El Colegio de San Luis, 7(14), 141-170. Recuperado de https://www.redalyc.org/articulo.oa?id=426252094006.

García Pereyra, R. (2010). Ciudad Juárez la fea: Tradición de una imagen estigmatizada. Ciudad Juárez: Universidad Autónoma de Ciudad Juárez.

González Ramadall, M. (2004). Sociedad y deporte: Análisis del deporte y su reflejo en los medios de comunicación en España (Tesis doctoral). Universidad de la Coruña, La Coruña. Recuperado de https://ruc.udc.es/dspace/handle/2183/806.

Juárez, R., y Lara-Rodríguez, L. (2016). El deporte en Ciudad Juárez, 1950-2010». Chihuahua Hoy, 14, 479-523. DOI: 10.20983/chihuahuahoy.2016.14.18.

Llopis Goig, R. (ed.) (2009). Futbol postnacional: Transformaciones sociales y culturales del «deporte global» en Europa y América Latina. Barcelona: Anthropos.

Magazine, R., Martínez, S., y Ramírez, J. (2011). México y Ecuador: Dos distintas formas de construir la nación desde el futbol. Convergencia: Revista de Ciencias Sociales, 
18(56), 181-213. Recuperado de http://www.scielo.org.mx/pdf/conver/v18n56/ v18n56a8.pdf.

Magazine, R., Martínez, S., y Varela. S. (coords.) (2012). Afición futbolística y rivalidades en el México contemporáneo: Una mirada nacional. México: Universidad Iberoamericana.

Medina Pérez, C., Bass Zavala, S., y Fuentes Flores, C. (2019). La vulnerabilidad social en Ciudad Juárez, Chihuahua, México: Herramientas para el diseño de una política social. Revista INVI, 34(95), 197-223. Recuperado de https://revistainvi.uchile.cl/index.php/INVI/article/view/63088/67008.

Mendoza, O., y García, J. (2018). «nálisis del desarrollo histórico de la industria maquiladora de exportación en México: Caso de Ciudad Juárez, Chihuahua. Revista Doxa, 8(15), 135-152. DOI: 10.52191/rdojs.2018.74.

Monárrez Fragoso, J. E. (2000). La cultura del feminicidio en Ciudad Juárez, 1993-1999. Frontera Norte, 12(23), 87-117. Recuperado de http://www.scielo.org.mx/ pdf/fn/v12n23/v12n23a4.pdf.

Monárrez Fragoso, J. E. (2019). Feminicidio sexual sistémico: Impunidad histórica constante en Ciudad Juárez, víctimas y perpetradores. Estado \& Comunes, 1(8), 85-110. DOI: 10.37228/estado comunes.v1.n8.2019.99.

Rivera, E. (1999). México en sus regiones socioculturales deportivas. Revista Digital Efdeportes, 4(13). Recuperado de https://www.efdeportes.com/efd13/erivera.htm.

Rojas Blanco, C. E. (2020). Coyunturas retóricas entre lo político y lo moral: Políticas de contención ante los derechos de las mujeres en Ciudad Juárez (2002-2018). Ciudad Juárez: Universidad Autónoma de Ciudad Juárez.

Salazar, S. (2010). El mercadeo de la barbarie: Paisajes de violencia en la frontera norte de México. Perfiles Latinoamericanos, 36, 99-119. Recuperado de http://www.scielo.org.mx/pdf/perlat/v18n36/v18n36a4.pdf.

Sumano, J. A (2018). La violencia en Ciudad Juárez: A seis años de la estrategia Todos Somos Juárez. Recuperado de https://seguridad.nexos.com.mx/?p=897.

Taylor, L. D. (2003). Los orígenes de la industria maquiladora en México. Comercio Exterior, 53(11), 1045-1057. Recuperado de http://revistas.bancomext.gob.mx/ rce/magazines/59/7/RCE.pdf.

Vila, P. (2007). Identidades fronterizas: Narrativas de religión, género y clase en la frontera México-Estados Unidos. Ciudad Juárez: Universidad Autónoma de Ciudad Juárez.

Wood, D. (2021). Cien años de goledad: Medios, literatura y futbol globalizado. En T. Fischer, R. Köhler y S. Reith, S. (eds.), Futbol y sociedad en América Latina (pp. 377393). Madrid: Iberoamericana Vervuert. 